\title{
Costing Break Down of Fully Fashioned Knitwear
}

\section{A. T. M. Mohibullah ${ }^{*}$ (1) , Umme Magreba Takebira1, Saiful Islam², Md. Abdur Rahman Robin', Mustafizur Rahman Shipto1, Razu Ahmed1, Md. Fazlay Rabby1, Laila Zaman1}

\author{
${ }^{1}$ Department of Apparel Manufacturing \& Technology, BGMEA University of Fashion \& Technology, Dhaka, Bangladesh \\ ${ }^{2}$ Department of Textile and Fashion Management (DTFM), ISTT, Dhaka, Bangladesh \\ Email: *mohib@buft.edu.bd
}

How to cite this paper: Mohibullah, A.T.M., Takebira, U.M., Islam, S., Robin, Md.A.R., Shipto, M.R., Ahmed, R., Rabby, Md.F. and Zaman, L. (2020) Costing Break Down of Fully Fashioned Knitwear. Journal of Textile Science and Technology, 6, 153-167. https://doi.org/10.4236/jtst.2020.64013

Received: March 6, 2020

Accepted: September 27, 2020

Published: September 30, 2020

Copyright (c) 2020 by author(s) and Scientific Research Publishing Inc. This work is licensed under the Creative Commons Attribution International License (CC BY 4.0).

http://creativecommons.org/licenses/by/4.0/

\begin{abstract}
Fully fashioned knitwear has a problem that the texture and dimension of the garment, consumption and costing cannot be decided until the pattern is sincerely knitted and carried out environs of stipulations involved in the knitting process. The study finds out a total regular consumption, costing system and its parameters that are required to make a cost sheet of knitwear (sweater). The analysis gives the complete manner of sweater costing with the recommended aid of inspecting the elements that have an impact on costs. Required consumption and costing techniques such as yarn, trims, accessories, testing, rate of manufacturing and $\mathrm{FOB}$ are on hand in this study about exhibiting a special model of costing. The cost sheet consists of huge costs incurred at an extensive range of tiers of business operations. The analysis intends to show off from received tech pack to closing cost sheet. Therefore, the producers will obtain a sturdy reflection of a sweater costing method. Effective costing suggests the way to exist in this internationally competitive market.
\end{abstract}

\section{Keywords}

Costing, Consumption, Fully Fashioned Knitwear, Sweater, Tech Pack

\section{Introduction}

Fully fashioned is the foremost stylish garment for winter. There is no simple manufacturing system or manufacturing method, sketch shape and costing manner for typical knitwear like woven garments and limit and sew knitwear. This type of the product produces versatile fashions with the aid of altering machine set-ups [1]. The fully fashioned knitwear style producers are no longer making the remarkable fastidious of garment nor does it rank as a fashion/fancy 
garment in the global apparel market. The world market is however categorized as a furnish of low to medium and a quantity of style/fancy great garment in the international apparel market that is a massive mission to maintain in the world fashion market for apparel manufacturers. The clothing exporters' developing worldwide areas maybe no longer produce a fancy product for bulk manufacturing due to inadequate manufacturing implement and apparent method of costing and its factors. It is tough to exist in the world market if pricing is now not viable. Therefore, that to sustain in this competitive market, it is indispensable for all producers to supply first-class luminous products at a competitive cost [2]. Different factories are the utilization of a variety of strategies of costing and fashioning method that is too intricate to use for manufacturing as well as time-consuming. There is no meticulous record of fashioning frequency calculation, method of costing and publicity that there is no past query about this. Fully fashioned knitwear is made through a process of shaping a knitted shape by using developing or decreasing the variety of needles or wales. The individual parts are more arrange so that every garment piece is made with no more significant fabric and the portions are in fact, knitted together at the seam. Some entirely long-established knitwear is Sweater, Pullover and Cardigan, etc. [3]. Costing is the device of estimating and identifying the total rate of producing a garment, consists of the materials cost, prices of knitting, processing, finishing, fee of making, transportation as appropriate as the well-known charges of running the industrial business enterprise [4]. The technique of costing will fluctuate in accordance with product specification and style. The primary motives for costing are the pricing of the garments and order acceptance. Pricing of the garment can be completed via the potential of manufacturing fee delivered with estimated mark-up or profits share with it, negotiate the cost with the purchaser and decide whether to take shipping of the order or no longer [5]. A costing sheet consists of the rate of raw materials, trims and add-ons cost, CM fee and others. Enough facts and trips are very a correct deal necessary for doing worthwhile pricing. In addition, an exchange grasp about textiles is indispensable to make first-rate costing [6]. All these costs are accountable for closing costs. Making entire garment requirements to keep a supply chain or process in which value and depreciation costs are additionally delivered on the costing sheet [7]. Costing things to do such as buy of yarn, knitting, dyeing, fabrication cost, all resources cost, CM cost, print, embroidery, wash, carton costing, poly consumption, take a seem at cost, inspection cost, enterprise cost, earnings and cargo cost. These locate out about presents practical costing techniques in the RMG industry. It consists of all manufacturers are adding the use of software application to reduce the large consequence of costing [8]. If the producers are no longer performed with the costing properly, there is a sturdy hazard to be overthrown with the useful resource of the competitor. The goal of this locate out about is to present the ordinary costing manner of fully-fashioned knitwear. The study provides about continues the sequence of the entire costing sheet of a sweater in RMG industry. The analysis gives technical package deal assessment 
strategies and influencing factors that are affected via skill of entire costing. This research about additionally emphasized and presents thoughts about the aspects of costing such as raw materials (yarn, trims and accessories), value-added offerings (embroidery, washing, etc.), trying out of the garment, logistics cost, profits of the manufacturing organization, etc. In addition, it affords the records of the charge of a product. There is no draw spherical additionally for the enchantment of fashioning frequency calculation, consumption and cost. As top as graph growth practices have been imparting an evident appreciation of arriving at our objectives thoroughly typical as a ready-to-wear. It is unavoidable to provide a fashionable fashioning frequency calculation, consumption and value with all manageable established and independent costing elements to supply an ideal dimensional garment for each unique importer.

\section{Costing Method}

Costing is the key process along with all the other processes in merchandising. The contract of a visible costing of production will make the effortless processes to complete the whole work of merchandising. In the first stage of the cost of the sweater, sample needs to make first as per requirement style, size specification and weight. Per dozen sweaters weight need to be calculated. Wastage percentages, which may differ in different stage, also need to be added. Technical package analysis, measurement specification, product pattern, weight of the sample, raw material consumption like yarn consumption and costing, trims and accessories consumption and cost, production cost, washing cost, commercial charge, and profit are the important points of sweater costing.

\subsection{Technical Package}

A technical package (tech pack) assimilates a good deal of information that a manufacturer needs to produce the entire garment and it is reducing the chances of confusion about sample and production between buyer and supplier [9]. It consists of different and vital data respect to arranging an item such as buyer name, supplier name, shipment date, style no, style title, season, colors, fabric or yarn details, label placement, care instruction, etc. so, it bears complete information about the product. Primarily, the manufacturer checks the full tech pack very carefully. Mainly, they analyzed the product and specified its style. Figure 1(a) and Figure 1(b) show a product tech pack that was manufactured for Autumn Winter fashion. The product was a striped sweater that was consisted of soft-touch yarn. The product was made by three different colors yarn; those are Blue Harbour, Navy and Light Gray Marl. The style name of this product was AW19_SOFTTOUCH_STRIPE. The source of the tech pack and details were collected from a reputed sweater factory. The neck style of this product was crew neck and rib $1 \times 1$. The product was knitted $18 \mathrm{~cm}$ from HPS by Light Gray Marl yarn than knitting $1 \mathrm{~cm}$ by Blue Harbour Yarn and after that $0.5 \mathrm{~cm}$ by Light Gray Marl knitting was done. Continuously $0.3,0.5,1,0.5$, and $1 \mathrm{~cm}$ knitting 


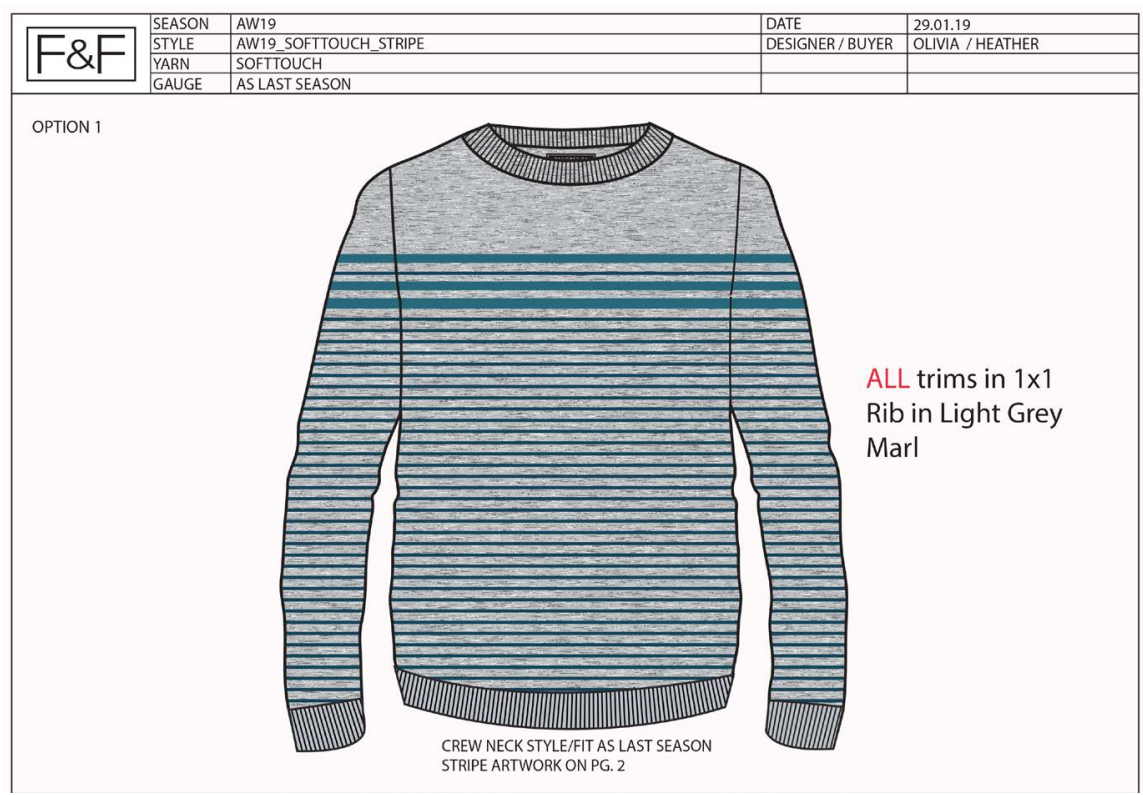

(a)

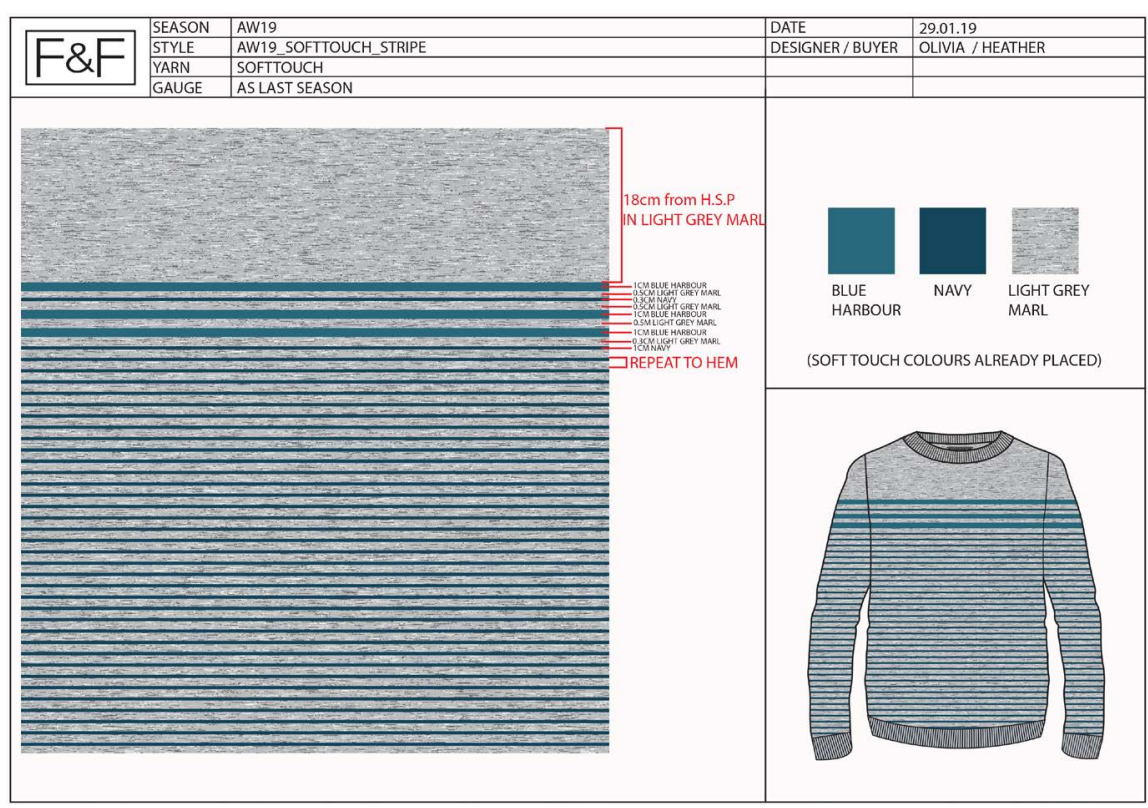

(b)

Figure 1. (a) Tech pack of a crew neck, rib $1 \times 1$ sweater. Source: Style AW19_Softtouch_ Stripe; (b) Tech pack for yarn color and color management.

were completed by Navy, Light Gray Marl, Blue Harbour, Light Gray Marl and Blue Harbour respectively. Lastly, Light Gray Marl and $1 \mathrm{~cm}$ knitting by Blue Harbour for the repeat to them finished $0.3 \mathrm{~cm}$ knitting. Cuff, hem and neck were made by rib.

\subsection{Measurement Specification}

The measurement specification sheet (Table 1) that demonstrates the knitting pattern instructions, general sizing or measurement information is the main 
Table 1. Measurement specification sheet.

\begin{tabular}{|c|c|c|c|c|c|c|c|c|c|c|}
\hline & Measuring Point flat in $\mathrm{cm}$ & $\begin{array}{c}\mathrm{XS} \\
32-34\end{array}$ & $\begin{array}{c}\text { S } \\
35-37\end{array}$ & $\begin{array}{c}\mathrm{M} \\
38-40\end{array}$ & $\begin{array}{c}\mathrm{L} \\
41-43\end{array}$ & $\begin{array}{c}\mathrm{XL} \\
44-46\end{array}$ & $\begin{array}{c}2 X L \\
47-49\end{array}$ & $\begin{array}{c}3 X L \\
50-52\end{array}$ & $\begin{array}{c}4 \mathrm{XL} \\
53-55\end{array}$ & All gauges \\
\hline 1 & Across Shoulder & 37 & 39 & 41 & 43 & 45 & 47 & 49 & 51 & $+/-1.0$ \\
\hline 2 & Across Front @ 15 cm below SNP & 32 & 34 & 36 & 38 & 40 & 42 & 44 & 46 & $+/-1.0$ \\
\hline 3 & Chest@ $2.5 \mathrm{~cm}$ below underarm & 44 & 48 & 52 & 56 & 60 & 65 & 70 & 75 & $+/-1.0$ \\
\hline 4 & Hem Width (Relaxed) & 34 & 35 & 42 & 46 & 50 & 55 & 60 & 65 & $+/-1.0$ \\
\hline 5 & Front Neck Drop & 7 & 7.5 & 8 & 8.5 & 9 & 9.5 & 10 & 10.5 & $+/-0.5$ \\
\hline 6 & Neck Width Back & 17.3 & 17.9 & 18.5 & 19.1 & 19.7 & 20.3 & 20.9 & 21.5 & $+/-0.5$ \\
\hline 7 & Back Neck Drop From Imaginary Line & 1.5 & 1.5 & 1.5 & 1.5 & 1.5 & 1.5 & 1.5 & 1.5 & $+/-0.5$ \\
\hline 8 & Across Back@15cm below SNP & 33 & 35 & 37 & 39 & 41 & 43 & 45 & 47 & $+/-1.0$ \\
\hline 9 & Front Length SNP $<$ Less than 72 & 69 & 70 & 71 & 72.5 & 74 & 75.5 & 77 & 78.5 & $+/-1.0$ \\
\hline 10 & Front Length SNP $<$ More than 75 & -2 & -1 & 0 & 1 & 2 & 3 & 4 & 5 & $+/-1.0$ \\
\hline 11 & Sleeve Length From Underarm long & 51 & 51 & 51 & 51 & 51 & 51 & 51 & 51 & $+/-1.0$ \\
\hline 12 & Armhole Straight & 23 & 24 & 25 & 26 & 27 & 28 & 29 & 30 & $+/-1.0$ \\
\hline 13 & Sleeve Bicep @ $2.5 \mathrm{~cm}$ below armhole & 16 & 17 & 18 & 19 & 20 & 21 & 22 & 23 & $+/-0.5$ \\
\hline 14 & Raglan Length Front & -2 & -1 & 0 & 1 & 2 & 3 & 4 & 5 & $+/-1.0$ \\
\hline 15 & Sleeve Opening & 8 & 8.5 & 9 & 9.5 & 10 & 10.5 & 11 & 11.5 & $+/-0.5$ \\
\hline 16 & Neck Depth & 2 & 2 & 2 & 2 & 2 & 2 & 2 & 2 & \\
\hline 17 & Cuff Depth & 6 & 6 & 6 & 6 & 6 & 6 & 6 & 6 & $+/-0.3$ \\
\hline \multirow[t]{2}{*}{18} & Hem Depth & 6 & 6 & 6 & 6 & 6 & 6 & 6 & 6 & $+/-0.3$ \\
\hline & MockShirt Measurement & & & & & & & & & \\
\hline 19 & Shoulder Seam & 13 & 13.6 & 13 & 14.8 & 15.4 & 16 & 16.6 & 17.2 & 0.5 \\
\hline 20 & Back Neck Width & 14.4 & 15.2 & 14.4 & 16.8 & 17.6 & 18.4 & 19.2 & 20 & 0.5 \\
\hline 21 & Back Neck Drop & 1.2 & 1.4 & 1.2 & 1.8 & 2 & 2.2 & 2.4 & 2.6 & 0.5 \\
\hline 22 & Front Neck Drop & 7.6 & 7.9 & 7.6 & 8.5 & 8.8 & 9.1 & 9.4 & 9.7 & 0.5 \\
\hline 23 & Neck Circumference & 37.5 & 39.5 & 37.5 & 43.5 & 45.5 & 47.5 & 49.5 & 51.5 & 0.5 \\
\hline 24 & $\begin{array}{l}\text { Collar Stand Depth At Centre } \\
\text { Back- Edge to stitch line }\end{array}$ & 4.4 & 4.4 & 4.4 & 4.4 & 4.4 & 4.4 & 4.4 & 4.4 & 0.3 \\
\hline 25 & Collar Stand Depth At Centre Back & 3.1 & 3.1 & 3.1 & 3.1 & 3.1 & 3.1 & 3.1 & 3.1 & 0.3 \\
\hline 26 & Collar Point-Blade Length & 4.5 & 4.5 & 4.5 & 4.5 & 4.5 & 4.5 & 4.5 & 4.5 & 0.3 \\
\hline 27 & $\begin{array}{l}\text { The Space-Top Button Fastened, } \\
\text { Taken Top Edge of Stand }\end{array}$ & 1 & 1 & 1 & 1 & 1 & 1 & 1 & 1 & 0.3 \\
\hline 28 & Collar Spread & 6 & 6 & 6 & 6 & 6 & 6 & 6 & 6 & 0.5 \\
\hline 29 & Collar leap edge & 35 & 37 & 35 & 41 & 43 & 45 & 47 & 49 & 0.5 \\
\hline 30 & Yoke Depth at CB & 9.5 & 10 & 10.5 & 11 & 11.5 & 12 & 12.5 & 133 & 0.5 \\
\hline
\end{tabular}

component of the tech pack. Usually, garments have been labeled using many different size systems that have resulted in varying sizing methods between different manufacturers made for different countries due to changing demograph- 


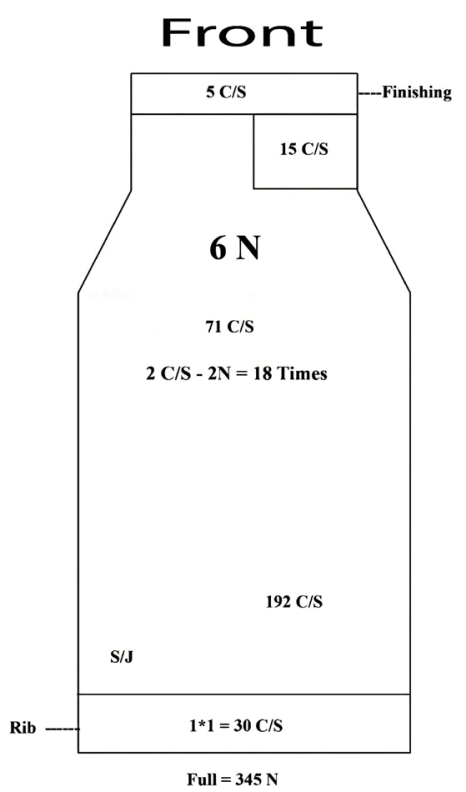

ics and increasing rates of size. The requirements of measurement charts are often contradictory as in trying to provide the best fit using a minimum number of sizes [10].

\subsection{Product Pattern}

Fully fashioned knitwear merchandise is made through a process of shaping a knitted structure by increasing or decreasing the number of needles or wales which is followed by the pattern. Patterns of the product need to analysis for production. A semi-automatic knitting machine was used to manufacture the product where operators were input and command to the machine as per the pattern design. The pattern always plays a vital role and it was a critical step to make accurate samples for collecting execute orders from buyers. Accurate pattern making helps to eliminate fabric waste [11]. Contemporary methods of fashion construction create fifteen percent waste of the total fabric [12]. Garment components are separated to determine the machine setup and also be analyzed the SMV of that product for knitting and linking.

It is reliant on the stretch and recovery factor moreover shrinkage, elongation after knitting the garment. It is also impossible to signify the dimension of the fully-fashioned knitwear before finishing. The number of wale and course and unit of loops (Figure 2) specifies the design of the sweater.

\subsection{Raw Material Consumption}

Yarn is the main raw material of the sweater. Sweater yarns are soft and thicker than cut and sew knitwear like t-shirt, polo-shirt yarns. Sweater needs more comfort and warmth. For manufacturing product Style AW19_Softtouch_Stripe (Figure 1(a) \& Figure 1(b)), required three colors yarn which was Blue Harbour,

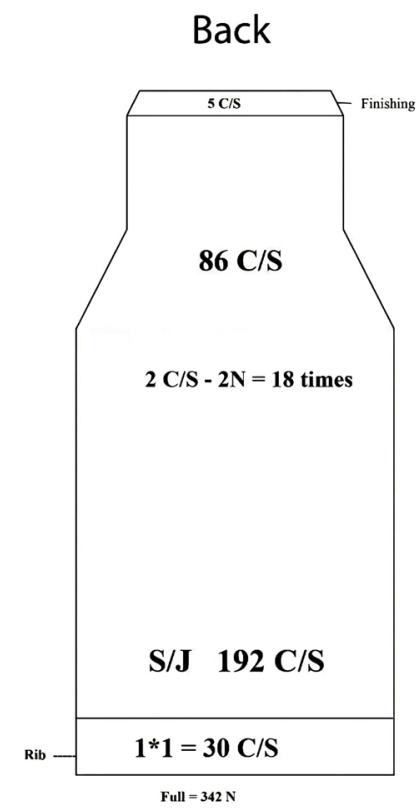

Sleeve

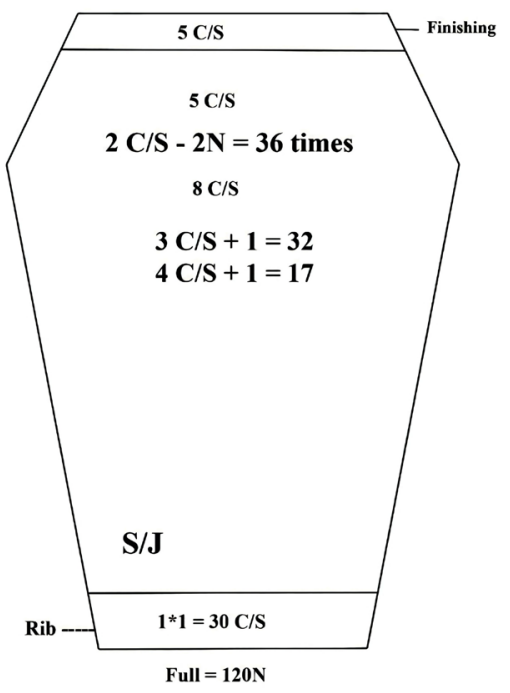

Figure 2. Product pattern. 
Navy and Light Gray Marl. More colors were increasing the cost of a product slightly. On the other hand, trims and accessories were also analyzed. Label, embroidery, motif, etc. are mainly used for a sweater as trims and price tag, hangtag, poly, carton, etc. used as accessories. For Style AW19_Softtouch_Stripe sewing thread and label were used as trims.

\subsection{Yarn Consumption}

Generally, pure acrylic, cotton, wool, acrylic mélange, blended acrylic, mixed cotton, mixed wool, chenille, angora and cashmere yarns are used for sweater manufacturing. During ensuring yarn quality strength and comfort are more focused [13]. It was calculated specifically in the pattern analyzing stage to determine total yarn consumption (Table 2).

\subsection{Trims Consumption}

Labels are generally used in fully-fashioned knitwear and threads are generally used for attaching where quantity and consumption of both labels and threads as well as all trims are mentioned in Table 3.

\subsection{Accessories and Other Consumption}

All required accessories and other quantity and consumption are discussed in Table 4.

\subsection{Required Test}

Test cost, wash cost, overhead cost, etc. are included as other costs. Different

Table 2. Yarn consumption.

\begin{tabular}{cccccccc}
\hline Size & S & M & L & Xl & 2xl & 3xl & Total \\
\hline Qty & 167 & 367 & 418 & 351 & 217 & 150 & 1670 pcs. \\
Wt/Dz & & & & Av. W’t-7.80 & & \\
Light Grey Marl 50\% (lbs) & 54 & 119 & 136 & 114 & 71 & 49 & $543 \mathrm{lbs}$ \\
Navy 28\% (lbs) & 30 & 67 & 76 & 64 & 39 & 27 & $303 \mathrm{lbs}$ \\
Blue Harbous 22\% (lbs) & 24 & 52 & 60 & 50 & 31 & 21 & $238 \mathrm{lbs}$ \\
Yarn Req. Without Wastage (lbs) & 108 & 238 & 272 & 228 & 141 & 97 & $1084 \mathrm{lbs}$ \\
Yarn Req. With 7\% Wastage (lbs) & 116 & 255 & 291 & 244 & 151 & 104 & $1161 \mathrm{lbs}$ \\
\hline
\end{tabular}

Table 3. Trims consumption sheet.

\begin{tabular}{cccccc}
\hline Items Name & Supplier & $\begin{array}{c}\text { Consumption } \\
\text { per Dozen }\end{array}$ & $\begin{array}{c}\text { Garment } \\
\text { Quantity }\end{array}$ & Wastage\% & $\begin{array}{c}\text { Total } \\
\text { Quantity }\end{array}$ \\
\hline Care Label (Regular) & MAXIM & $12 \mathrm{pc}$ & 1670 & 5 & $1754 \mathrm{pcs}$ \\
Main Label & SML & $12 \mathrm{pc}$ & 1670 & 4 & $1737 \mathrm{pcs}$ \\
Size Label & SML & $12 \mathrm{pc}$ & 1670 & 5 & $1754 \mathrm{pcs}$ \\
Sewing Thread & A\&E & 0.15 cone & 1670 & 10 & 23 cones \\
\hline
\end{tabular}


Table 4. Accessories and other consumption sheets.

\begin{tabular}{cccccc}
\hline Objects Name & Supplier & $\begin{array}{c}\text { Consumption } \\
\text { Per/Dzn. }\end{array}$ & $\begin{array}{c}\text { Garment } \\
\text { Quantity }\end{array}$ & Wastage\% & Total Quantity \\
\hline Carton Sticker & Montrims & 12 & & 5 & $1753 \mathrm{pcs}$ \\
Poly Sticker & Montrims & 12 & 5 & $1754 \mathrm{pcs}$ \\
Poly & BENGAL & 12 & 5 & $1754 \mathrm{pcs}$ \\
Blister & BENGAL & 2 & 3 & $287 \mathrm{pcs}$ \\
Carton & KDS & 0.67 & & 3 & $97 \mathrm{pcs}$ \\
Hanger & TIC & 12 & & 3 & $1721 \mathrm{pcs}$ \\
Sizer & TIC & 12 & 1670 & 3 & $1721 \mathrm{pcs}$ \\
Security Tag & TIC & 12 & & 4 & $1737 \mathrm{pcs}$ \\
Paper Gum Tape & Western & 0.1 & & 5 & $15 \mathrm{pcs}$ \\
Scotch Tape & Local & 0.2 & & 5 & $30 \mathrm{pcs}$ \\
Plastic Tag Pin & Local & 12 & & 5 & $1735 \mathrm{pcs}$ \\
RF ID & R-PAC & 12 & & 4 & $1737 \mathrm{pcs}$ \\
\hline
\end{tabular}

types of testing ensure product quality. Chemical and physical both testing are essential for fully-fashioned knitwear. The most common physical testing are GSM count, yarn count, colorfastness to washing, colorfastness to water, stretch and recovery, abrasion resistance, tear strength, smoothness retention, tensile strength, pilling resistance, etc. Chemical testing absorbency test, $\mathrm{pH}$ test, moisture test, formaldehyde, etc. also need a sweater to make certain product quality.

\subsection{Production Cost}

Manufacturers are calculating actual production costs (Table 5) while the assertion of an order to make accurate costing of a product. Besides that, it provides an idea about the required time of received order production. In this stage, manufacturers analyzed the CM charge usually. It refers to manufacturing cost or labor cost of a dozen [14]. Production costs can include a variety of expenses, such as labor, raw materials, consumable manufacturing supplies, and general overhead [15]. It must be required to know the knitting, linking productivity and finishing cost to calculate the CM (cost of manufacturing). Finishing included labor cost of trimming, mending, ironing, etc. are the standard wage is calculated $\$ 6.70 /$ day in average sweater factories for knitting, linking operators. The knitting productivity for this product was 9 pieces/day, so the knitting cost was $\$ 0.74 /$ pcs. On the other hand, the linking productivity was 15 pieces/day, so the linking cost is $\$ 0.45 / \mathrm{pcs}$. Knitting and linking time varied with the style of the product and winding required average time for all solid objects. It takes longer for stripe and designed items. The manufacturer was received yarn in hank shape form suppliers and had to require transforming the cone form.

\section{Final Cost Sheet and Discussion}

A cost sheet (Table 6(a) \& Table 6(b)) is a statement that consists of the various 
Table 5. CM calculation.

\begin{tabular}{cccc}
\hline DESCRIPTION (Labor cost) & COST & DESCRIPTION (CM cost) & COST \\
\hline Winding/Pc & $\$ 0.0290$ & Total Labor cost/pc & $\$ 1.4085$ \\
Knitting/Pc & $\$ 0.7444$ & Prod Bonus/pc (25\%) & $\$ 0.3521$ \\
Linking/Pc & $\$ 0.4467$ & Fixed (overhead) cost/pc (70\%) & $\$ 0.9859$ \\
Trimming \& Mending/Pc & $\$ 0.0750$ & Total Cost/pc & $\$ 2.7465$ \\
Iron/Pc & $\$ 0.0500$ & TOTAL Cost/Dzn. & $\$ 32.958$ \\
Zipper Attachment/Pc & $\$ 0.00$ & Profit/Dzn. $(20 \%)$ & $\$ 6.5916$ \\
Fabric Attachment/Pc & $\$ 0.00$ & TOTAL CM/DZN. & $\$ 39.5496$ \\
Button Attachment/Pc & $\$ 0.00$ & & \\
Misc/Pc & $\$ 0.0625$ & & \\
Total Labor cost/pc & $\$ 1.4085$ & & \\
\hline
\end{tabular}

Table 6. (a) Final cost sheet; (b) Final cost sheet.

(a)

\begin{tabular}{|c|c|c|c|}
\hline \multicolumn{4}{|c|}{ COST SHEET } \\
\hline Factory & $\mathrm{ABC}$ & Report Date & 20-Dec-18 \\
\hline Buyer & TESCO (UK) & Time & 1:20 P.M \\
\hline Season & AW-19 & Order Qty(Dz) & 139 \\
\hline Order No & & FOB $\mathrm{Px} / \mathrm{Dz}$ & $\$ 64.80$ \\
\hline Style No & ES025000 & $\mathrm{CM} \mathrm{Px} / \mathrm{Dz}$ & $\$ 41.10$ \\
\hline Order Qty. (pcs) & 1670 & GG: & 12 \\
\hline GMT Description & V NECK SOFT TOUCH & Merchandiser ID: & $1,700,000$ \\
\hline Mode of Payment: & TT/LC & Merchandiser Name: & Mr. X \\
\hline
\end{tabular}

(b)

\begin{tabular}{|c|c|c|c|c|c|c|c|c|c|}
\hline $\mathrm{Sl}$ & Description & Supplier & Cons/Dz & Unit & Rate/Unit & Waste\% & $\begin{array}{c}\text { Total } \\
\text { Cost } / \mathrm{Dz}\end{array}$ & $\begin{array}{c}\text { Required } \\
\text { (Pcs/lbs/con) }\end{array}$ & T. Order Cost \\
\hline \multicolumn{10}{|c|}{ A. Yarn Information } \\
\hline 1 & 100\% ACRYLIC CASH LIKE 2/36 & LUGANG & 7.8 & lbs & $\$ 1.45$ & 7 & $\$ 12.11$ & 1162 & $\$ 1684.90$ \\
\hline 2 & PC DYEING (Body + Rib yarn) & S.SUHI & 7.8 & lbs & $\$ 0.20$ & - & $\$ 1.67$ & 1165 & $\$ 233.00$ \\
\hline 3 & ACRYLIC COVERED NYLON (for rib) & ANSWELL & 0.0165 & lbs & $\$ 17.30$ & 12 & $\$ 0.32$ & 2.57 & $\$ 44.46$ \\
\hline \multicolumn{7}{|c|}{ Total Yarn Cost } & $\$ 14.10$ & & $\$ 1962.36$ \\
\hline \multicolumn{10}{|c|}{ B. Trim and Accessories Information } \\
\hline 4 & Care Label (Regular) & MAXIM & 12 & pcs & $\$ 0.01$ & 5 & $\$ 0.11$ & 1754 & $\$ 15.79$ \\
\hline 5 & Main Label & SML & 12 & pcs & $\$ 0.02$ & 4 & $\$ 0.29$ & 1737 & $\$ 39.95$ \\
\hline 6 & Size label & SML & 12 & pcs & $\$ 0.01$ & 5 & $\$ 0.14$ & 1754 & $\$ 19.29$ \\
\hline 7 & Carton Sticker & Montrims & 0.67 & pcs & $\$ 0.04$ & 3 & $\$ 0.03$ & 96 & $\$ 4.03$ \\
\hline 8 & Poly sticker & Montrims & 12 & pcs & $\$ 0.01$ & 5 & $\$ 0.15$ & 1754 & $\$ 21.05$ \\
\hline
\end{tabular}




\section{Continued}

\begin{tabular}{|c|c|c|c|c|c|c|c|c|c|}
\hline 9 & Sewing thread & A \& E & 0.15 & cones & $\$ 0.95$ & 10 & $\$ 0.16$ & 23 & $\$ 21.85$ \\
\hline 10 & Poly & BENGAL & 12 & pcs & $\$ 0.05$ & 5 & $\$ 0.64$ & 1754 & $\$ 89.45$ \\
\hline 11 & Blister & BENGAL & 2 & pcs & $\$ 0.08$ & 3 & $\$ 0.16$ & 287 & $\$ 22.96$ \\
\hline 12 & Carton & KDS & 0.67 & pcs & $\$ 1.65$ & 3 & $\$ 1.14$ & 96 & $\$ 158.40$ \\
\hline 13 & Hanger & TIC & 12 & pcs & $\$ 0.13$ & 3 & $\$ 1.59$ & 1720 & $\$ 221.88$ \\
\hline 14 & Sizer & TIC & 12 & pcs & $\$ 0.01$ & 4 & $\$ 0.11$ & 1737 & $\$ 15.63$ \\
\hline 15 & Security tag & TIC & 12 & pcs & $\$ 0.06$ & 5 & $\$ 0.72$ & 1754 & $\$ 99.98$ \\
\hline 16 & Paper Gum Tape & Western & 0.1 & Roll & $\$ 1.85$ & 5 & $\$ 0.20$ & 15 & $\$ 27.75$ \\
\hline 17 & Scotch Tape & Local & 0.2 & Roll & $\$ 0.20$ & 5 & $\$ 0.04$ & 29 & $\$ 5.80$ \\
\hline 18 & Plastic tag pin & Local & 12 & pcs & $\$ 0.01$ & 10 & $\$ 0.13$ & 1837 & $\$ 18.37$ \\
\hline 19 & RF ID & R-PAC & 12 & pcs & $\$ 0.11$ & 4 & $\$ 1.36$ & 1737 & $\$ 189.33$ \\
\hline \multicolumn{7}{|c|}{ Total Trims and accessories Cost } & $\$ 6.98$ & & $\$ 971.52$ \\
\hline \multicolumn{10}{|c|}{ C. VALUE ADDITION } \\
\hline 20 & Inspection & ITS & 1 & pcs & $\$ 0.10$ & 12 & $\$ 0.11$ & 156 & $\$ 15.60$ \\
\hline 21 & Others/test & BV & 1 & pcs & $\$ 0.08$ & & $\$ 0.08$ & 139 & $\$ 11.12$ \\
\hline \multicolumn{6}{|c|}{ Total Value Addition } & & $\$ 0.19$ & & $\$ 26.72$ \\
\hline \multicolumn{6}{|c|}{ Sub Total cost/Cost of materials $(A+B+C)$} & & $\$ 21.27$ & & $\$ 2960.60$ \\
\hline 22 & \multicolumn{5}{|c|}{$\mathrm{CM}$} & & $\$ 39.55$ & 1670 & $\$ 5504.04$ \\
\hline \multirow[t]{2}{*}{23} & \multicolumn{5}{|c|}{ FOB } & & $\$ 60.95$ & & $\$ 8482.20$ \\
\hline & \multicolumn{5}{|c|}{$\mathrm{FOB} \operatorname{cost} / \mathrm{pc}$} & & \multicolumn{3}{|c|}{$\$ 5.079$} \\
\hline
\end{tabular}

costs incurred at several stages of business operations. The cost incurred in each unit of a product or service in a certain period [16]. A cost sheet provides an insight into organizational performance and efficiency. The costing sheet helps to competitive analysis and the improvement of the business operations through cost reduction [16].

The study provides an indispensable discovering in the cost sheet that takes hold of the yarn consumption and costing. The study confirmed the finding of (Figure 3(a)) 100\% ACRYLIC CASH LIKE 2/36 yarn presents utmost yarn cost even if its consumption was a bit lower than PC DYEING (Body + Rib yarn) yarn due to high price sourcing.

Another promising discovering used to be that (Figure 3(b)) in accordance with the consumption ratio acrylic cash like yarn needs $48 \%$ the place PC dyeing yarn desires 50\% for body and rib manufacturing and acrylic covered nylon yarn requirements $2 \%$ for rib in the production. But the cost effects validated that (Figure $3(\mathrm{c})$ ) acrylic cash like yarn takes $86 \%$ of whole price the position PC dyeing yarn takes a $12 \%$ and acrylic included nylon yarn takes completely $2 \%$ for total manufacturing. The end result highlights that little is mentioned about the sourcing and pricing of yarn as properly as maintaining quality.

The cost of trim and accessories consumption and cost effects show off two 


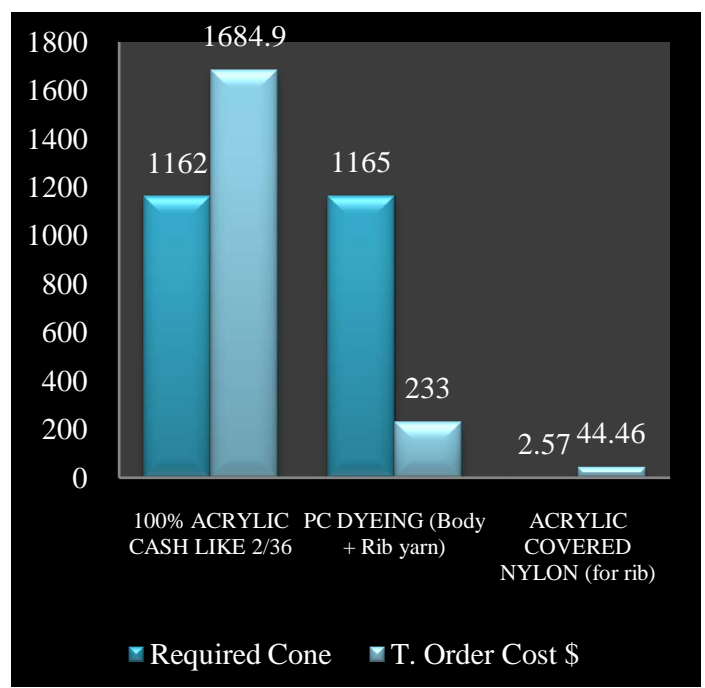

(a)

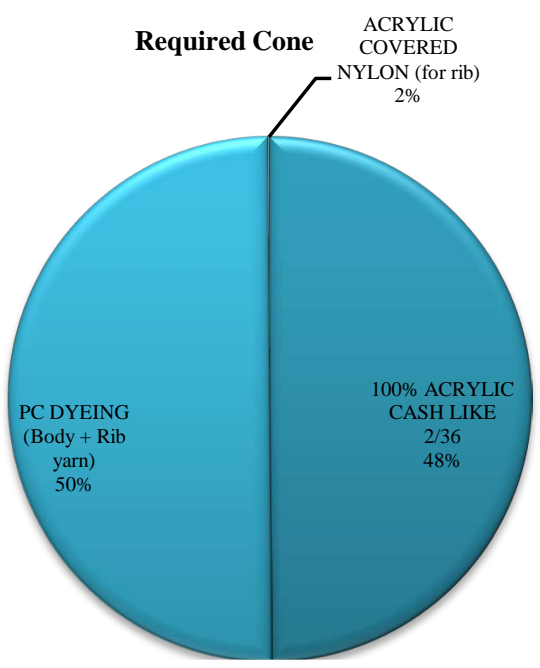

(b)

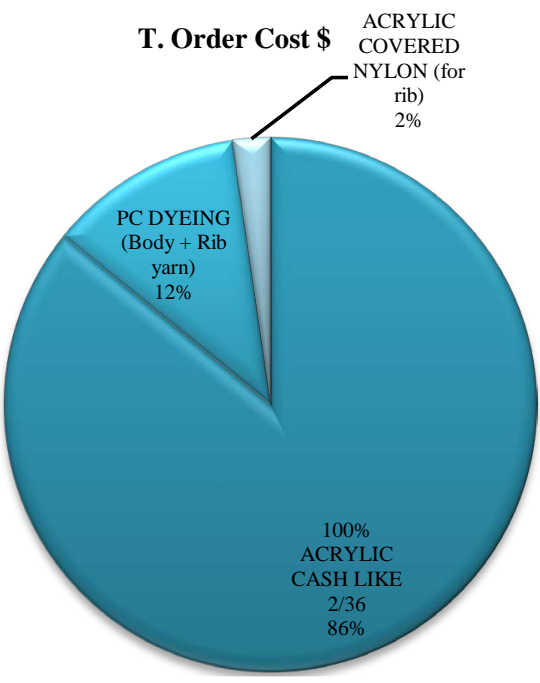

(c)

Figure 3. (a) Yarn consumption and cost; (b) Yarn consumption; (c) Yarn cost. 
things. First, the hanger costing is larger than accessories add-ons and second, RF ID rate is moreover higher than others cost. From the results, it is clear that cartoon, poly bag and safety tag additionally takes more share of entire trim and add-ons cost. A in a similar way novel discovering is that the most crucial trims stitching thread, care level, size level, etc. takes bit percentages of entire manufacturing cost. There is no look up on yarn and other materials price evaluation that is the predominant barrier of the current practice. Another drawback which is the leading cause for preparing these details and analysis of full documentation in a file is there are few complete archives on the previous shipment in the sweater factory (Figure 4).

All consumption was calculated such as yarn consumption, trims consumption and accessories consumption as per tech pack (Figure 1(a) and Figure 1(b)). In addition, market price was used to be analyzed of required materials and manufacturing cost. Cost sheet used to be made with the aid of calculating items, its price and waste percentage. The FOB rate consists of several kinds of cost. Within the entire FOB price, the majority of the rate used to be an inclination for $\mathrm{CM}$ of complete manufacturing cost. $\mathrm{CM}$ was once significantly affected by the FOB price that used to be $64.89 \%$. Then yarn, trims, add-ons, and fee addition used to be keeping chronologically $23.14 \%, 11.45 \%$ and $0.32 \%$. Generally, Price is variable as per quality, extent and variety. These easy findings are steady with lookup showing that a mixture of immoderate price yarn and low price yarn provides a great product as precise as limit cost. Other consequences had been mostly in line with accessories phase hanger in packaging has an extensive effect on final costing. It is important to highlight the fact that cut and the make cost of fully fashion still greater than woven and knit garments CM. The consequences highlight those raw materials supplies do not appear to effect on the whole percentage. From this standpoint, most consumer in the accessories area can be seen as negotiate substances to restrict value and provide a high-quality product (Figure 5).

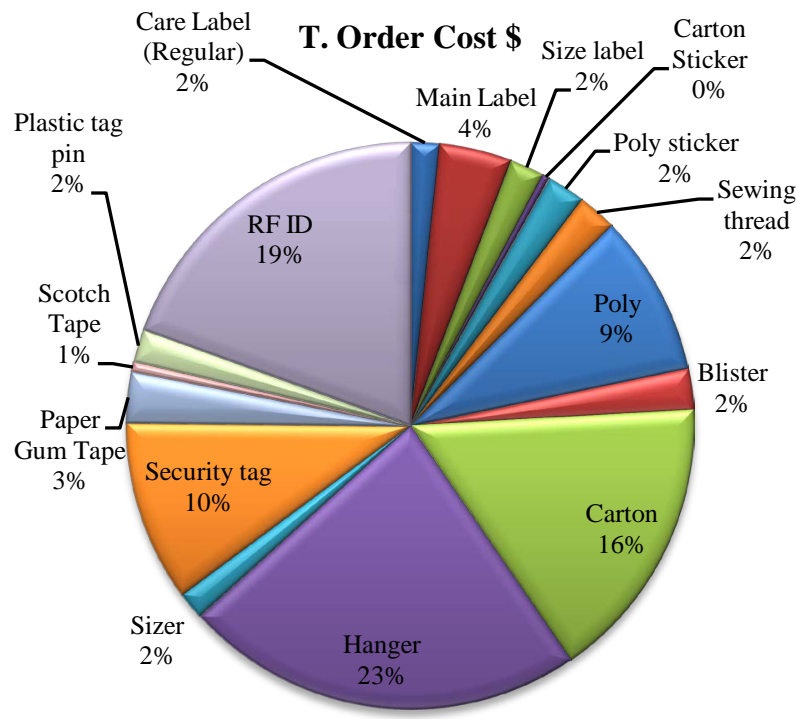

(a) 


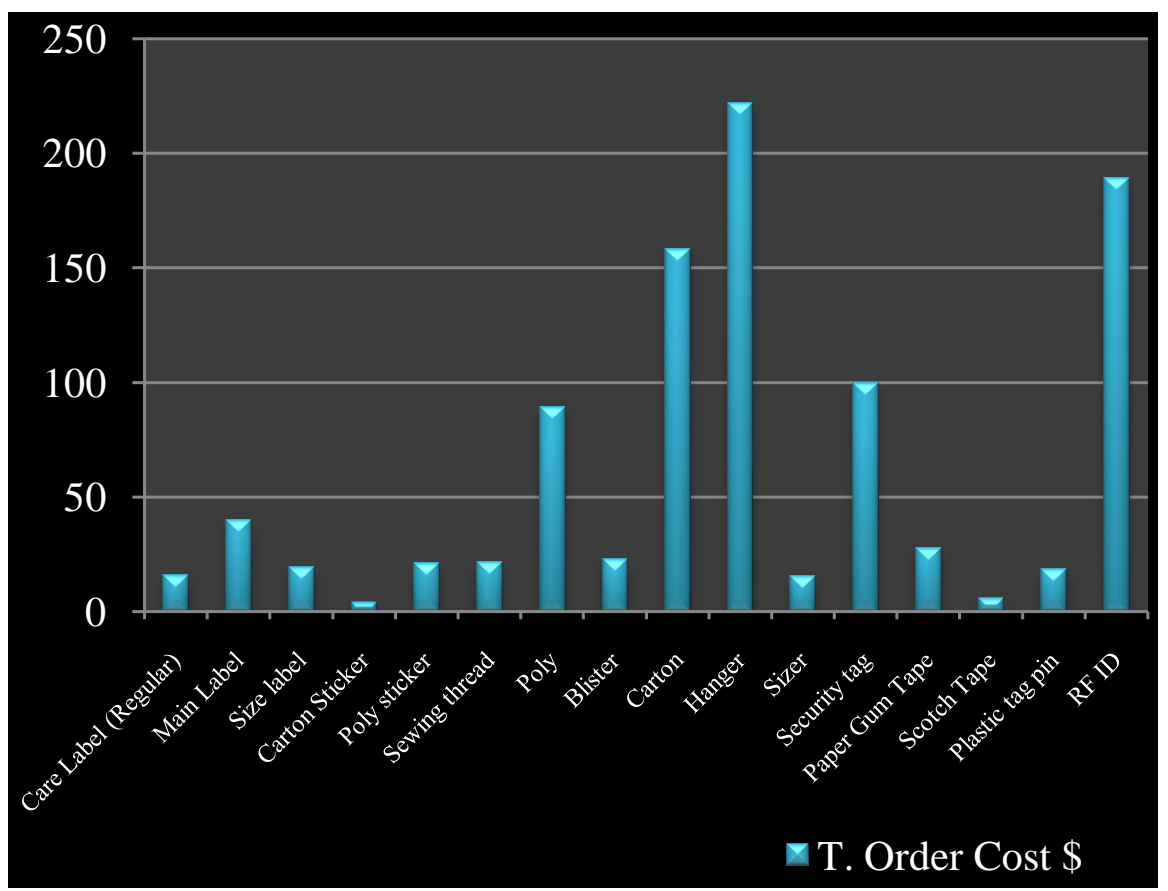

(b)

Figure 4. (a) consumption trim and accessories; (b) cost of trim and accessories.

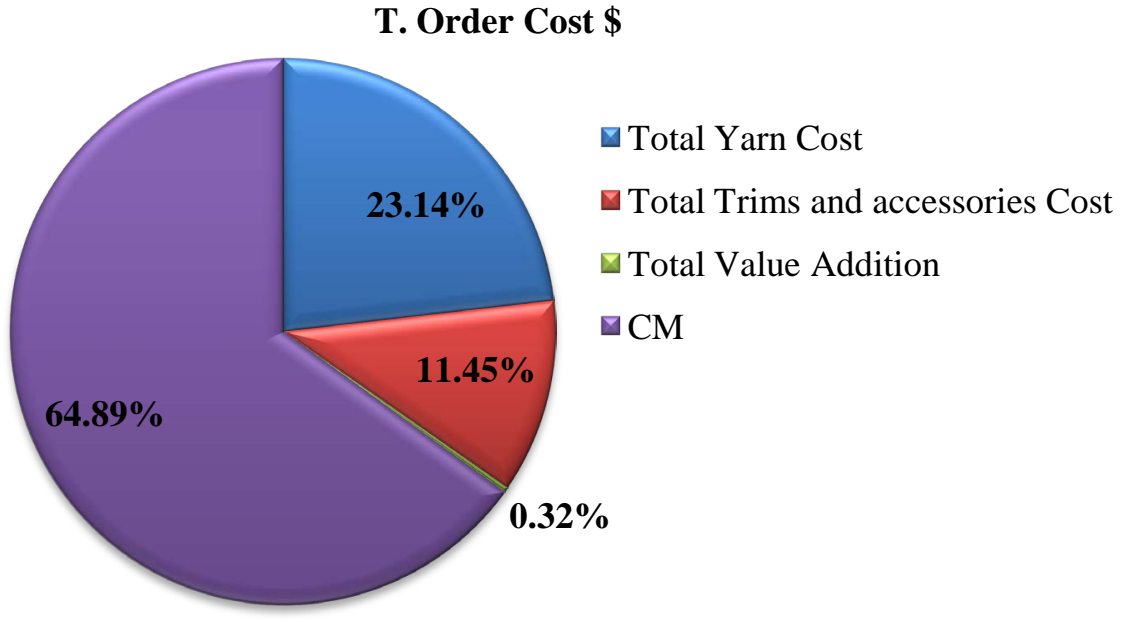

Figure 5. Total order cost percentage.

\section{Conclusion}

Exquisite costing affords the way to stay on in this competitive world market though competitors are significantly developing in the RMG sector. Therefore, the producers need understandable thoughts about costing and its influencing factors. By heading off imported raw material apparel producers will be in a role to limit cost of raw resources and lead time of the thoroughly trend fully fashion knitwear. The paper concludes by imparting the commonplace thoughts about the costing approach of a sweater. In addition, these findings furnish extra facts about the actual cost sheet consists of all charges such as yarn, trims, accessories, 
knitting, testing, CM, overhead cost, etc. The assessment leads to the following conclusion of raw materials consumptions that are required for making a cost sheet of a sweater. This conclusion follows from the truth that the cost of sweater manufacturing is increased than sewing knit garments. Results furnish a foundation for facts about the desired rate that differs from a sweater. This can also increase uncertainties about cost assessment and negotiate which can be addressed through the way of the parameter of effective costing.

\section{Conflicts of Interest}

The authors declare no conflicts of interest regarding the publication of this paper.

\section{References}

[1] Rajib, M.M.I. (2019) A Study on Laddering Effect Embedded in Fully Fashioned Knitwear Using Polyester Yarn. American Scientific Research Journal for Engineering, Technology, and Sciences (ASRJETS), 51, 1-12.

[2] Quaddus, M. (2015) Sustaining Competitive Advantage via Business Intelligence, Knowledge Management, and System Dynamics. Emerald Publishing, Irving, TX. https://doi.org/10.1108/S1069-096420150000022008

[3] Pawar, P. (2016) Global Sweater Industry 2016 Market Overview, Size, Share, Trends, Analysis, Technology and Applications. QYResearchReports.

[4] Choudhary, A.S. (2015) Cost Analysis in Garment Industry. International Journal of Recent Advances in Multidisciplinary Research, 2, 0702-0704

[5] Miah, M.S. (2014) Important Costing Tips for Garments. Textile Learner, Dhaka.

[6] Mokhtar, H. (2018) Textile Product Costing. Textileschool, SA.

[7] IndrèLapinskaite, J.K. (2014) The Impact of Supply Chain Cost on the Price of the Final Product. Business, Management and Education, 12, 109-126.

https://doi.org/10.3846/bme.2014.08

[8] Kenton, W. (2019) Production Costs. Investopedia, New York.

[9] Rita, A.A. and Mahamud, S. (2016) Effectiveness of Technical Packages for the Apparel Production Process in the Global Apparel Industry. IOSR Journals, 18, 47-51. https://doi.org/10.9790/487X-1809024751

[10] Gupta, D. (2004) A Statistical Model for Developing Body Size Charts for Garments. International Journal of Clothing Science and Technology, 16, 458-469. https://doi.org/10.1108/09556220410555641

[11] Naznin, K.N., Tabraz, M. and Sultana, S. (2020) Process \& Effective Methods of Pattern Making for the RMG (Ready-made Garment) Sector. Journal of Research \& Method in Education, 7, 46-48.

[12] ElaheSaeidi, V.W. (2017) Precious Cut: Exploring Creative Pattern Cutting and Draping for Zero-Waste Design. International Journal of Fashion Design, Technology and Education, 11, 243-253. https://doi.org/10.1080/17543266.2017.1389997

[13] Rocco Furferi, M.G. (2015) Yarn Strength Prediction: A Practical Model Based on Artificial Neural Networks. SAGE Journals, 2, Article ID: 640103.

[14] Career, A. (2016) Garments CM (Cost of Manufacturing) Calculation. 
http://apparelcareer.blogspot.com/

[15] Investopedia (2020) Production Cost. http://investopedia.com/

[16] Mohibullah, A.T.M. (2019) Costing Principles of a Denim Pant. Journal of Textile Science and Technology, 5, 48-60. https://doi.org/10.4236/jtst.2019.52005 